\title{
Territorial Organization of Direction-Selective Ganglion Cells in Rabbit Retina
}

\author{
David I. Vaney \\ Vision, Touch and Hearing Research Centre, Department of Physiology and Pharmacology, The University of Queensland, \\ Brisbane, Queensland 4072, Australia
}

The On-Off direction-selective (DS) ganglion cells in the rabbit retina comprise four discrete subtypes that orthogonally code the direction of image motion. This study examined the dendritic relationships between different subtypes of On-Off DS cells, which were identified by their distinctive type 1 bistratified (BiS1) morphology following the intracelIular injection of a biotinylated tracer or Lucifer yellow under direct microscopic control. The dendrites of BiS1 cells that had closely spaced somata, which presumably comprised subtypes of On-Off DS cells with different preferred directions, were not randomly superimposed but were fasciculated into loose bundles. By contrast, tracer coupling revealed that neighboring On-Off DS cells of one subtype were highly territorial, providing complete coverage of the retina with minimal overlap. This mirrors, on a larger scale, the territorial organization within the dendritic tree of individual DS cells, suggesting that similar interactions shape both the branching pattern and the spatial extent of these neurons. Moreover, the dendrites at the edge of the dendritic field often formed tip-to-shaft or tip-to-tip contacts with dendrites from coupled cells, thus appearing to form closed dendritic loops that may be equivalent to those found within the dendritic tree. Consequently, the dendrites of one subtype are distributed uniformly and economically across the retina. The resulting plexus forms a strikingly regular scaffold on which the presynaptic interneurons generate direction selectivity.

[Key words: retinal ganglion cell, direction selectivity, dendritic territories, tracer coupling, Neurobiotin, rabbit]

Direction-selective (DS) neurons respond optimally to stimulus movement in a "preferred" direction, but are inhibited by movement in the reverse "null' direction. In the rabbit retina, there are two distinct types of DS ganglion cells that give either On-Off or On-center responses to flashed illumination (Barlow et al., 1964). The On-Off DS cells comprise four physiological subtypes with preferred directions to the anterior, posterior, superior, and inferior (Oyster and Barlow, 1967). The On-Off DS cells in the rabbit retina can be readily distinguished from other retinal ganglion cells by their type 1 bistratified (BiS1)

\footnotetext{
Received Jan. 24, 1994; revised Apr. 4, 1994; accepted Apr. 13, 1994.

I thank Denise Crook, Charles Nelson, and Danny Thomas for expert technical assistance. D.I.V. holds a Senior Research Fellowship of the National Health and Medical Research Council (Australia).

Correspondence should be addressed to David I. Vaney, Ph.D., at the above address.

Copyright (C) 1994 Society for Neuroscience $0270-6474 / 94 / 146301-16 \$ 05.00 / 0$
}

morphology ( $\Lambda$ mthor et al., 1984, 1989; Famiglictti, 1987, 1992a; Yang and Masland, 1992; Oyster et al., 1993). The dendrites of these cells are narrowly stratified at $20 \%$ and $70 \%$ depth of the inner plexiform layer, in sublamina $a$ (Off) and sublamina $b$ (On), respectively. The terminal dendrites, which range from 3 rd to 15 th order, are distributed throughout the dendritic field in each sublamina and their retroflexive branching creates a regular space-filling lattice in which some dendrites appear to form closed loops. Examples of all four subtypes of On-Off DS cells have been injected with horseradish peroxidase or Lucifer yellow, but the preferred direction of a cell cannot be inferred from the pattern of dendritic branching.

Although the dendritic morphology and the receptive-field properties of individual DS cells have been well characterized, it was not known whether each subtype provides independent coverage of the retina. This study resolves the issue by taking advantage of the finding that tracer coupling labels the cellular array of one subtype of On-Off DS cells, which were identified by their distinctive BiS1 morphology (Vaney, 1990b, 1991). Photochromic intensification of the labeled cells now reveals that the dendritic trees of the coupled subtype are highly territorial, providing almost seamless coverage of the retina, despite pronounced variability in the shape and size of individual ganglion cclls.

Some of these findings were reported at the 1992 FASEB Summer Research Conference on Visual Processing and the 1993 ARVO Annual Meeting (Vaney, 1993).

\section{Materials and Methods}

Experiments were performed on adult pigmented rabbits of either sex in accord with the Australian code of practice for the care and use of animals for scientific purposes. Following anaesthesia with 4\% Halothane in air, $0.4 \mu \mathrm{g}$ of $4^{\prime}, 6$-diamidino-2-phenyl-indole (DAPI; Sigma) in $20 \mu \mathrm{l}$ of deionized water was injected into the vitreous, $1-2 \mathrm{~d}$ before pentobarbitone overdose and enucleation (Masland et al., 1984).

The preparation of the isolated retinal whole-mounts and the techniques for intracellular injection of identified neurons under direct microscopic control (Vaney, 1984) have been described in detail elsewhere (Hampson et al., 1992). In brief, the retinal preparations were superfused with carbogenated Ames medium (Sigma), containing $2.0 \mathrm{gm} /$ liter of $\mathrm{NaHCO}_{3}$ (pH 7.4 at room temperature) and $1 \mathrm{ml} /$ liter of fetal calf serum. The tips of the injection micropipettes were filled with either $4 \%$ Lucifer yellow (Sigma) in deionized water or $1-2 \%$ Lucifer Yellow and $3-4 \%$ $N$-(2-aminoethyl)-biotinamide hydrochloride (Neurobiotin; Vector Laboratories) in $0.1 \mathrm{~m}$ Tris buffer, $\mathrm{pH}$ 7.6. Lucifer yellow was iontophoresed into the impaled cell with $-1 \mathrm{nA}$ current for about $30 \mathrm{sec}$ whereas Neurobiotin was iontophoresed with $+0.5 \mathrm{nA}$ current for 1-2 min. In some of the early experiments, biocytin (Horikawa and Armstrong, 1988) was used instead of Neurobiotin (Kita and Armstrong, 1991; Vaney, 1991). The tracer-filled cells were left to equilibrate in Ames medium for $0.5-4 \mathrm{hr}$ before fixation in $4 \%$ paraformaldehyde for $40-60 \mathrm{~min}$. 


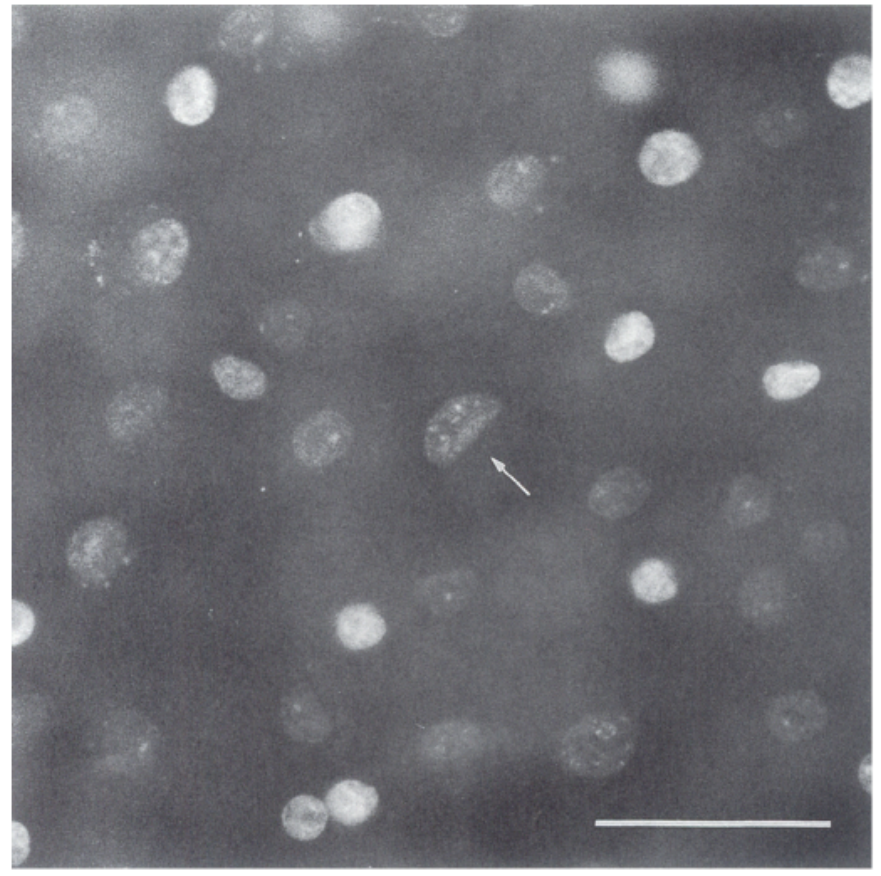

Figure 1. Fluorescence micrograph of a DAPI-labeled rabbit retina viewed under ultraviolet excitation, with the focus on the ganglion cell layer. The nuclei of displaced amacrine cells are smaller and brighter than those of adjacent ganglion cells. The large crescent-shaped nucleus (arrow) is indicative of a type 1 bistratified (BiS1) ganglion cell. Scale bar, $50 \mu \mathrm{m}$.

The cells filled with Neurobiotin or biocytin were visualized by incubating the retina with a streptavidin-biotinylated-HRP complex (Amersham) and then detecting the peroxidase activity using diaminobenzidine (DAB; Sigma) as the chromogen (Vaney, 1991). In some preparations, the $\mathrm{DAB}$ reaction product was photochromically intensified in the presence of $0.02 \%$ nitro blue tetrazolium in $0.1 \mathrm{M}$ Tris buffer, pH 8.2 (Vaney, 1992), either soon after DAB processing or, in some cases, up to 2 years later (e.g., Fig. 6). All of the cells illustrated in the paper have been photochromically intensified. The cells filled with Lucifer yellow were incubated with an antiserum to the dye (Pow et al., 1993), which was visualized by a modified ABC procedure (Vaney, 1992). The processed retinae were coverslipped in 50\% glycerine in phosphate buffer.

The injected cells were examined and photographed on a Zeiss Axioplan microscope and their dendritic trees were mapped directly under the drawing tube, using a $63 \times$ oil-immersion objective to confirm the dendritic relationships of overlapping cells. In order to reconstruct the dendritic plexus over an extended area, the dendritic trees of the coupled cells were individually mapped at medium power and then retraced over a montage of micrographs taken at lower power. Inked drawings of the coupled cells were digitized on a scanner and then graphically reconstructed on a Macintosh Quadra 950 using MACDRAw PRO.

The local density of coupled ganglion cells was calculated empirically using the mean distance from the soma of the injected cell to the five nearest somata of the tracer-coupled cells. In the reference field, which is mapped in Figure $4 B$, the 18 coupled cells had a density of 55 cells/ $\mathrm{mm}^{2}$ and the mean distance to the coupled somata was $145 \mu \mathrm{m}$. For all other tracer-coupled cells, the density was calculated from the mean distance using the following equation: cell density $=55 \times(145 /$ mean distance $)^{2}$.

\section{Results}

\section{Identification of type 1 bistratified ganglion cells}

In the ganglion cell layer of the rabbit retina, the fluorescent nuclear dye DAPI brightly labeled the uniform population of displaced cholinergic amacrine cells (Masland et al., 1984). Although the nuclei of adjacent ganglion cells were only weakly

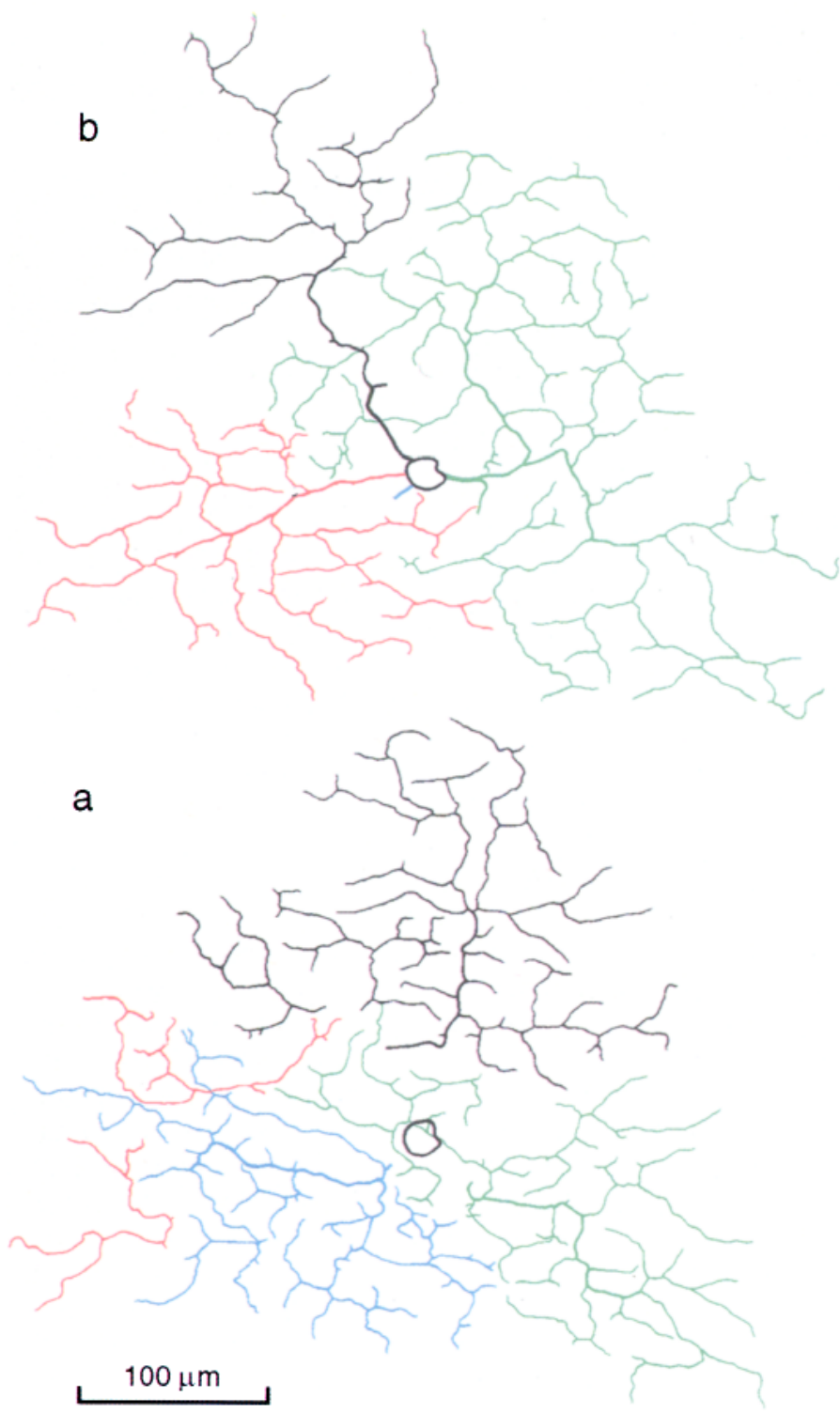

Figure 2. Graphic reconstruction of a rabbit retinal ganglion cell that was identified as an On-Off direction-selective cell from its BiS1 morphology. The dendrites in the On sublamina $(b)$ of the inner plexiform layer have been vertically separated from the overlapping dendrites in the Off sublamina $(a)$. The branching systems arising from each of the four primary dendrites are coded in different colors, showing that they tile the dendritic field with minimal overlap in each sublamina. This Neurobiotin-filled cell did not show tracer coupling to neighboring BiS1 cells. Retinal eccentricity: $5 \mathrm{~mm}$ below visual streak.

labeled, they were clearly defined and the somata could be readily impaled with a micropipette under direct visual control. When randomly selected ganglion cells were injected with Lucifer yellow in the isolated superfused retina, about $10 \%$ of the cells had a distinctive bistratified morphology corresponding to that of the On-Off direction-selective (DS) ganglion cells (see below). It became apparent that those cells with the type 1 bistratified (BiS1) morphology usually had a large crescent-shaped nucleus (Fig. 1). When this selection criterion was used, the success rate for impaling BiS1 ganglion cells was boosted to about $80 \%$ in the visual streak and mid-peripheral retina, with a lower success rate in the far periphery (Vaney et al., 1989). 


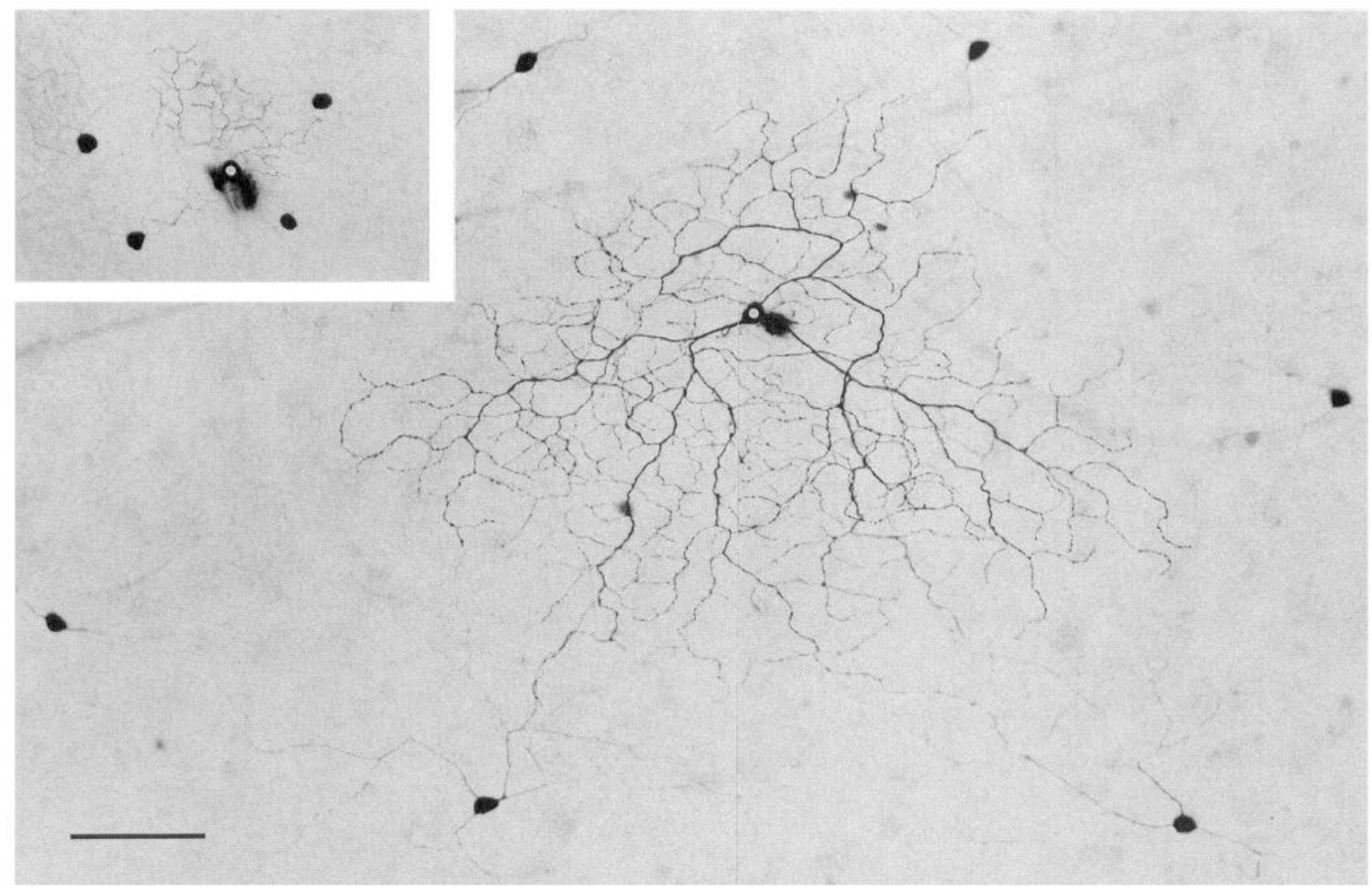

Figure 3. Neurobiotin-filled BiS1 cells in the far periphery and peak visual streak (inset) of the rabbit retina, viewed at the same magnification in photochromically intensified preparations. Each injected cell (white dot) shows homologous tracer-coupling to a ring of surrounding BiS1 cells, the somata of which are located outside the dendritic field of the injected cell. Retinal eccentricities: $9 \mathrm{~mm}$ and $0 \mathrm{~mm}$ (inset). Scale bar, $100 \mu \mathrm{m}$.

Although the initial selection of crescent-shaped nuclei was a subjective process, the subsequent identification of the BiS1 morphology was quite objective, because these cells have the most distinctive morphology of any ganglion cell type in the rabbit retina. The two to four primary dendrites of a BiS1 cell formed branching systems that tiled the dendritic field with minimal overlap in each sublamina of the inner plexiform layer (Fig. 2), as previously described for On-Off DS cells that had been injected with horseradish peroxidase (Oyster et al., 1993).

\section{Tracer-coupling pattern of BiS1 ganglion cells}

When the BiS1 ganglion cells in the superfused rabbit retina were injected with biocytin or Neurobiotin, many of the cells showed tracer coupling to surrounding ganglion cells of the same morphological type, as reported in preliminary form (Vaney, 1990b, 1991). Such homologous coupling was shown by 49 $(37 \%)$ of the 131 BiS1 ganglion cells that were well filled with biotinylated tracer. Seventeen of the 22 preparations contained three or more filled cells, which always comprised a mixture of coupled and noncoupled cells in proportions that did not vary markedly from the combined total $(37 \pm 12 \%, \pm \mathrm{SD})$.

There was no evidence that the time in vitro affected the incidence of tracer coupling, as shown by sequential preparations taken from the same rabbit. In one case, 17 ganglion cells in the left retina were injected 1-2 $\mathrm{hr}$ after enucleation; 10 of the cells were well filled, including eight BiS1 cells. In the right retina, 33 ganglion cells were injected $3-5 \mathrm{hr}$ after enucleation; 21 of the cells were well filled, including 16 BiS1 cells. In both retinae, $38 \%$ of the filled BiS1 cells showed tracer coupling.

The tracer-coupling pattern of the BiS1 cells was quite stereotyped in that the strongly labeled somata of the coupled ganglion cells, which formed a regular array around the injected soma, were usually located outside the dendritic field of the injected cell. Thus, the dendritic organization of the coupled BiS1 cells resembles that of each subtype (On or Off) of the $\alpha$-ganglion cells (Wässle et al., 1981a; Peichl et al., 1987). The BiS1 cells were directly tracer coupled to five to seven neighboring cells over most of the retina, but the small BiS1 cells on the peak visual streak were usually coupled to only four neighboring cells (Fig. 3).

The ring of BiS1 cells labeled by tracer coupling sometimes showed secondary coupling to an outer ring of somata, particularly in photochromically intensified preparations (see Fig. $3 b$ of Vaney, 1991). Thus, a continuous array of about 20 coupled cells was labeled, enabling the local cell density to be measured with some precision.

Some of the BiS1 ganglion cells that showed strong homologous coupling also showed weaker heterologous coupling to scattered amacrine cells of diverse types that did not appear to contact the injected soma or the pipette track (see Figs. 9, 11). Such "inappropriate" coupling (Vaney, 1994) cannot be attributed to artifactual fusion of the cell membranes by the advancing micropipette (Kaneko et al., 1981), because it was associated 


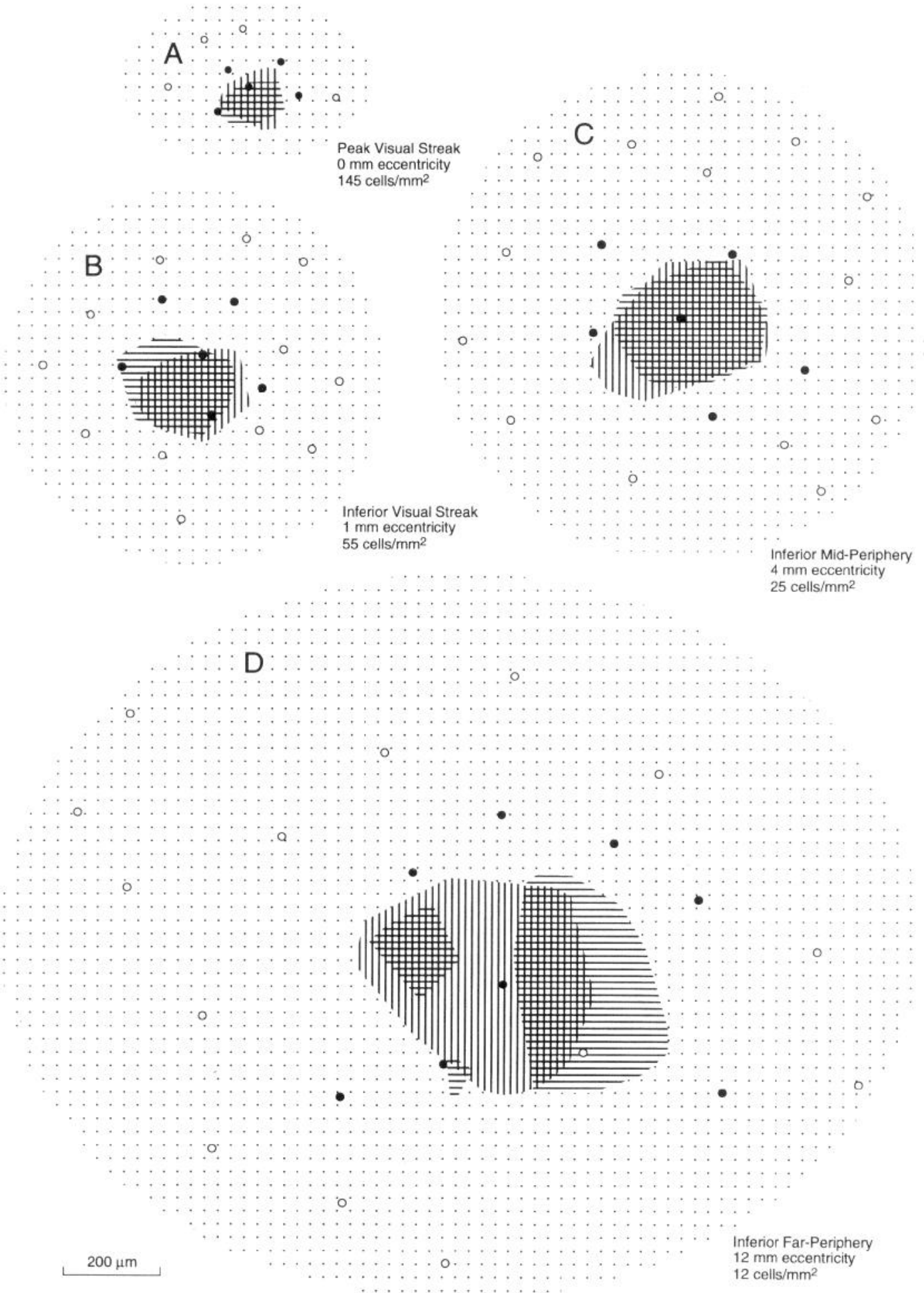

Figure 4. Graphic representation of the somatic array of tracer-coupled BiS1 cells at different eccentricities from the visual streak. For each injected cell, the dendritic fields are shown separately for sublamina $a$ (horizontal hatching) and sublamina $b$ (vertical hatching). Micrographs of fields $A$, $D$, and $B$ are shown, respectively, in Figures 3 and 11 of this article, and Figure $3 b$ of Vaney (1991).

only with coupled BiS1 cells and not with the noncoupled BiS1 cells.

\section{Dendritic-field size of BiS1 ganglion cells}

Following the practice of Oyster et al. (1993), the dendritic field in each sublamina was delimited by line segments joining ad- jacent dendritic terminals on the perimeter of the traced cell, thus forming a complex polygon that outlined deep indentations in the arborization. The resulting area was about $20 \%( \pm 8 \%$ SD) smaller than the equivalent dendritic field delimited by a conventional convex polygon (Famiglietti, 1992a).

The dendritic-field size of the coupled BiS1 cells increased 


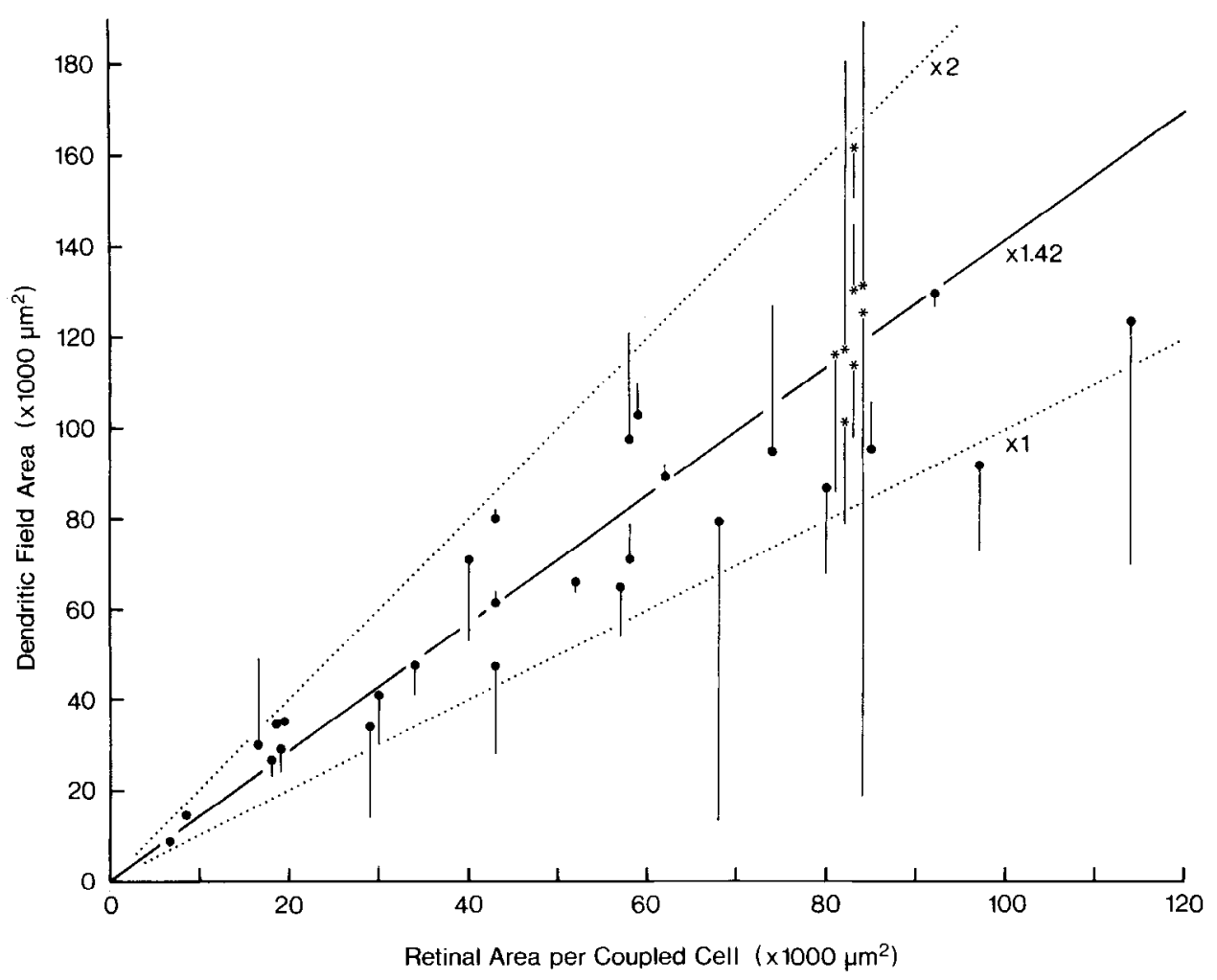

Figure 5. Graph of dendritic-field area as a function of retinal area per cell (the inverse of cell density) for the tracercoupled BiS1 cells. Each point marks the mean area of the two fields in sublaminae $a$ and $b$, whereas the termination point of the vertical line marks the dendritic-field area in sublamina $b$. The 27 black dots represent separate injected cells and the asterisks represent an array of eight coupled cells that are reconstructed in Figure 12. The local dendritic-field coverage can be calculated by multiplying the dendritic-field area by the cell density: all but one of the cells showed a one- to twofold coverage (dotted lines), with a mean coverage of 1.42 (solid line). with retinal eccentricity from the horizontal visual streak (Fig. 4). The smallest cell, which was located in the peak visual streak, had a dendritic-field area of $7900 \mu \mathrm{m}^{2}$ in sublamina $a(100 \mu \mathrm{m}$ equivalent diameter) and $9200 \mu \mathrm{m}^{2}$ in sublamina $b(108 \mu \mathrm{m}$ equivalent diameter). This cell was comparable in size to the smallest On-Off DS cell injected by Amthor and his colleagues (6800 $\mu \mathrm{m}^{2}$ in sublamina $a$ and $7300 \mu \mathrm{m}^{2}$ in sublamina $b$; Oyster et al., 1993). By contrast, the coupled BiS1 cells located more than $10 \mathrm{~mm}$ from the visual streak were almost 20 times larger, typically having a dendritic-field area in each sublamina of about $130,000 \mu \mathrm{m}^{2}$ (407 $\mu \mathrm{m}$ equivalent diameter).

The dendritic-field area of the noncoupled BiS1 cells appeared to match that of coupled BiSl cells at each retinal eccentricity, as shown by an analysis of 14 pairs of injected cells located outside the visual streak. On average, the summed dendritic fields of the coupled BiS1 cell were $1.04( \pm 0.22 \mathrm{SD})$ times larger than those of the adjacent noncoupled cell.

\section{Cell density and dendritic-field coverage}

The density of coupled BiSI cells in the peak visual streak was calculated to be 145 cells $/ \mathrm{mm}^{2}$, thus accounting for $3 \%$ of the ganglion cells, which have a peak density of about 5000 cells/ $\mathrm{mm}^{2}$ (Provis, 1979; Vaney, 1980; Oyster et al., 1981, 1987; Hughes, 1985). The density of coupled BiSl cells dropped rapidly on the shoulders of the visual streak, reaching 55 cells $/ \mathrm{mm}^{2}$ at I $\mathrm{mm}$ eccentricity, and then declined more gradually with eccentricity in peripheral retina (Fig. 4).

The dendritic-field area of the coupled BiS1 cells increased almost linearly with the retinal area per coupled cell (the inverse of cell density), indicating that the dendritic-field coverage was relatively constant across the retina (Fig. 5). For 28 injected cells located from the peak visual streak to the far periphery, the sublamina $a$ fields showed a coverage of $1.49 \pm 0.37( \pm S D)$, the sublamina $b$ fields showed a coverage of $1.34 \pm 0.56$, and the summed fields $/ 2$ showed a coverage of $1.42 \pm 0.28$. Thus, the sublamina $a$ fields of these drawn cells were $11 \%$ larger than the sublamina $b$ fields, but the difference was not significant because of the great variability in the relative size of the two fields.

The lower variance for the summed fields reflects the finding that those BiSl cells that had an extra-large dendritic field in one sublamina, usually had an extra-small field in the other sublamina. Consequently, all but one of the coupled BiSl cells had a dendritic-field coverage between 1.0 and 2.0 for the summed fields $/ 2$. In two extreme cases, the arborization in sublamina $b$ was largely vestigial and, thus, these nominally bistratified cells were essentially monostratified. One of these cells is shown in Figure 12: the sublamina $b$ arborization occupied $19,000 \mu \mathrm{m}^{2}$ (158 $\mu \mathrm{m}$ equivalent diameter), giving a theoretical coverage of only 0.2 ; the greatly expanded arborization in sublamina $a$ occupied $232,000 \mu \mathrm{m}^{2}$ ( $543 \mu \mathrm{m}$ equivalent diameter), giving a theoretical coverage of 2.8 . By contrast, the summed fields $/ 2$ had a coverage of 1.5 , which was close to the mean value for coupled BiS 1 cells.

\section{Overlap of coupled and noncoupled BiSl cells}

About $63 \%$ of the well filled BiS1 cells did not show tracer coupling and it seemed probable that they comprised subtypes of On-Off DS cells that were distinct from the coupled subtype(s). Exhaustive mapping of small patches of retina with an intraocular recording electrode had indicated that On-Off DS cells with overlapping receptive fields have different preferred directions (He et al., 1992). It was expected, therefore, that a coupled array of BiS1 cells should be extensively overlapped by noncoupled subtypes, analogous to the overlap of the On- and 


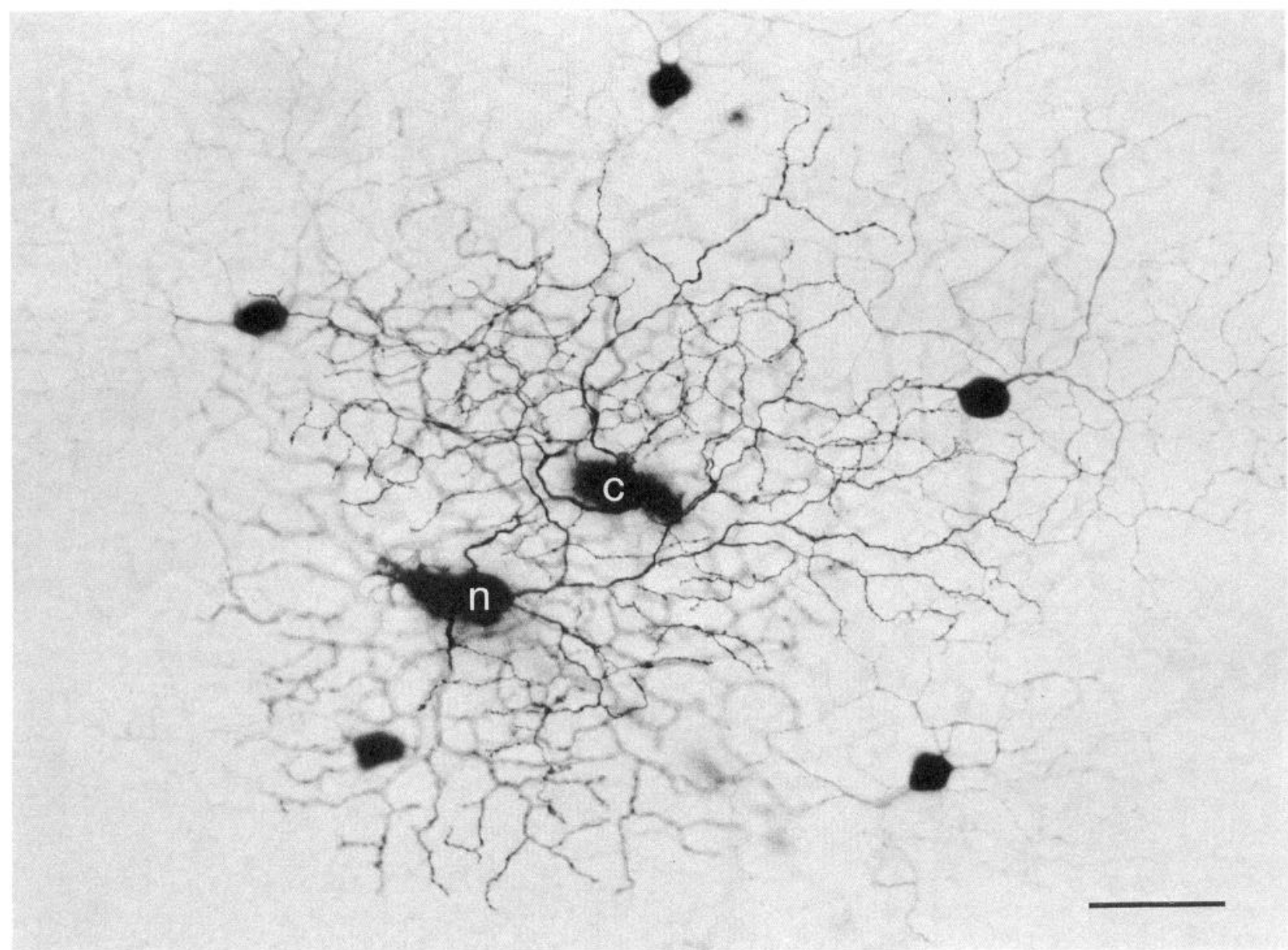

Figure 6. Micrograph of the sublamina $b$ arborizations of two Neurobiotin-injected BiS1 cells that have closely spaced somata and overlapping dendritic fields, presumably comprising On-Off DS cells with different preferred directions. The central cell is homologously coupled $(c)$ to five $\mathrm{BiS} 1$ cells of the same subtype, whereas the other injected cell is noncoupled $(n)$. Retinal eccentricity: $2 \mathrm{~mm}$ below visual streak. Scale bar, $50 \mu \mathrm{m}$.

Off-subtypes of $\alpha$-ganglion cells (Wässle et al., 1981a; Peichl et al., 1987).

This was confirmed by Neurobiotin injections of pairs or triplets of BiS1 cells that had closely spaced somata, presumably comprising On-Off DS cells with different preferred directions (Fig. 6). Successful filling of overlapping BiSl cells was achieved in seven cases, comprising five pairs of cells and two triplets. In five of these cases, including the two triplets, one cell showed tracer coupling and the other cell(s) did not; in the other two pairs, neither cell showed tracer coupling. There were no pairs in which both injected cells showed coupling to separate arrays of ganglion cells. These findings suggest that the BiS1 cells comprised one coupled subtype and two or more noncoupled subtypes. The dendrites from different $\mathrm{BiS} 1$ cells crossed above and below each other, indicating that the subtypes of On-Off DS cells were not microstratified within each sublamina.

\section{Dendritic fasciculation of overlapping cells}

Although the somata and dendritic fields of overlapping BiS1 cells were spatially independent, the dendrites tended to fasciculate in loose bundles, particularly in sublamina $a$ where the branching frequency is higher (Famiglietti, 1992a). When triplets of BiS1 cells were injected with Neurobiotin or Lucifer yellow, fascicles containing three dendrites were sometimes ob- served in the region of triple overlap (Fig. 7), indicating that the dendritic fasciculation probably involves all subtypes of OnOff DS cells, and not just pairs of subtypes with opposite preferred directions.

In such preparations, it was difficult to trace accurately the fasciculated dendrites to their cells of origin. The following strategy was adopted to overcome this problem (Vaney et al., 1989). A single BiS1 cell was filled with Lucifer Yellow and then photographed under fluorescence excitation in the tissue chamber before an overlapping BiS1 cell was injected with Lucifer yellow; the focal series of fluorescence micrographs enabled the dendritic trees to be disentangled and separately mapped following the immunoperoxidase reaction (Fig. 8).

\section{Territorial organization of tracer-coupled cells}

In order to map the extended dendritic plexus formed by the coupled subtype of $\mathrm{BiS} 1$ cells, the labeling contrast was increased by photochromic intensification of the DAB reaction product (Vaney, 1992). In a few outstanding preparations, this revealed the complete morphology of coupled cells, whose lightly labeled dendrites could usually be distinguished from those of the injected cell (Fig. 9). Graphic reconstruction of neighboring cells showed that, in each sublamina, the dendritic trees of coupled 

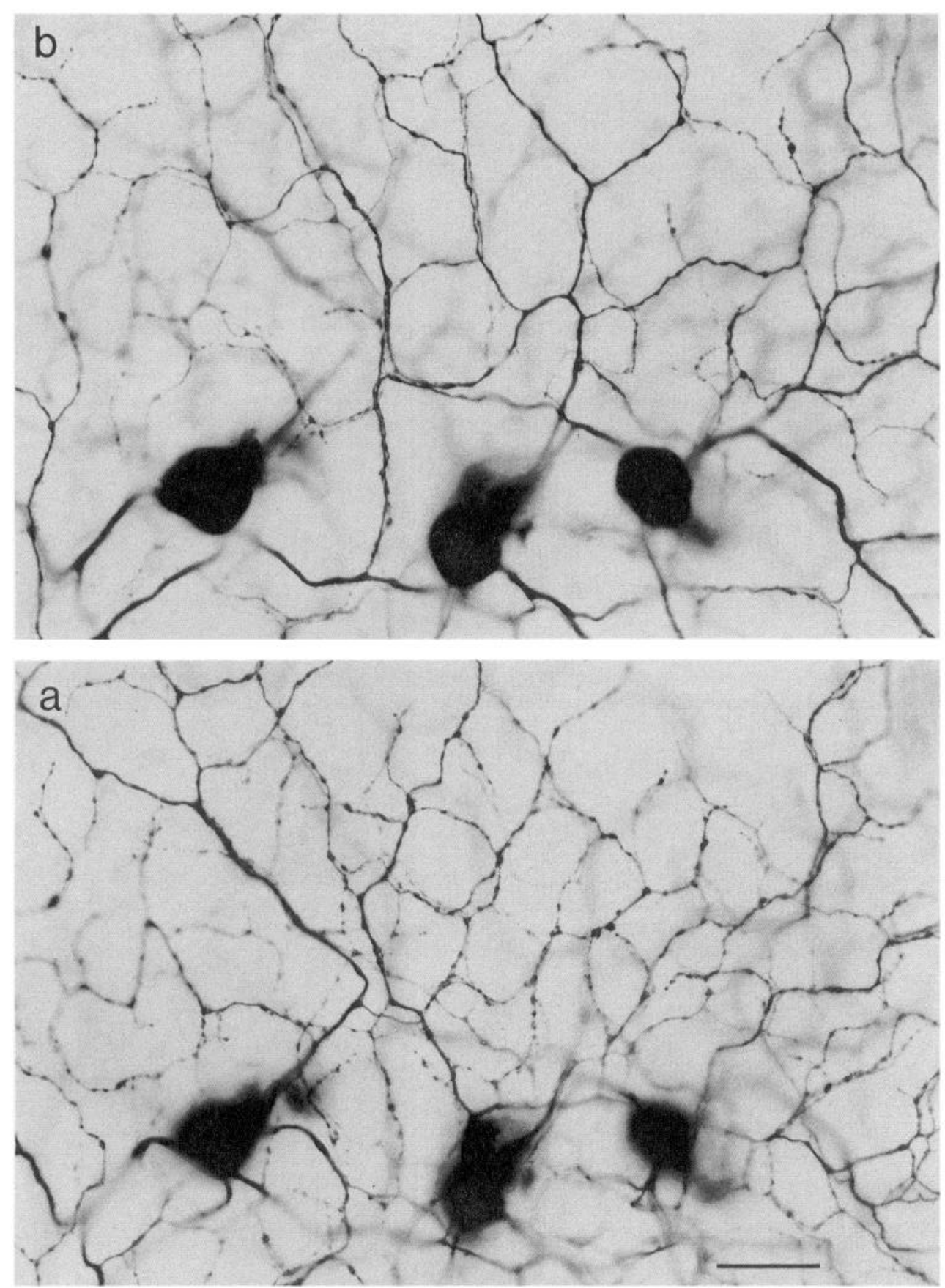

Figure 7. High-power micrographs of three BiS1 ganglion cells with closely spaced somata, presumably comprising On-Off DS cells with different preferred directions. The cells were injected with Lucifer yellow, which was made opaque by immunoperoxidase methods and photochromically intensified. The dendritic fields of the cells overlap substantially and their dendrites are fasciculated in both the On sublamina $(b)$ and the Off sublamina $(a)$. Retinal eccentricity: $3 \mathrm{~mm}$ below visual streak. Scale bar, $25 \mu \mathrm{m}$.
BiS1 cells provided complete coverage of the retina with little overlap. Consequently, the dendritic fields locked together with jigsaw precision, particularly in sublamina $b$ adjacent to the ganglion cell layer (Fig. 10).

The territorial organization of the coupled BiS1 cells was best demonstrated in a fortuitous preparation in which the injected cell was strongly coupled to seven neighboring cells (Fig. 11). Laborious reconstruction of the coupled array under high-power objectives showed that the neighboring dendritic fields in each sublamina were remarkably variable in their shape and size (Fig. 12). In fact, this local variability appeared to account for most of the scatter in dendritic-field size at a given density of BiS1 cells, with little contribution from individual variation (Fig. 5).
The reconstructed cells showed greater dendritic-field overlap in sublamina $a$ than sublamina $b$ and, correspondingly, the sublamina $a$ fields of these eight cells were $11 \%$ larger than the sublamina $b$ fields.

Although the sublamina $a$ arborization of each cell arose from the sublamina $b$ arborization, the two fields tended to be spatially independent, notwithstanding the inverse size relationship that was noted previously. Some cells gave rise to dendritic branches in sublamina $a$ that were separated from the major arborization, but these isolated dendrites occupied gaps within the surrounding dendritic trees. One coupled cell contacted the injected cell in sublamina $a$ only, while another coupled cell made contact in sublamina $b$ only. 


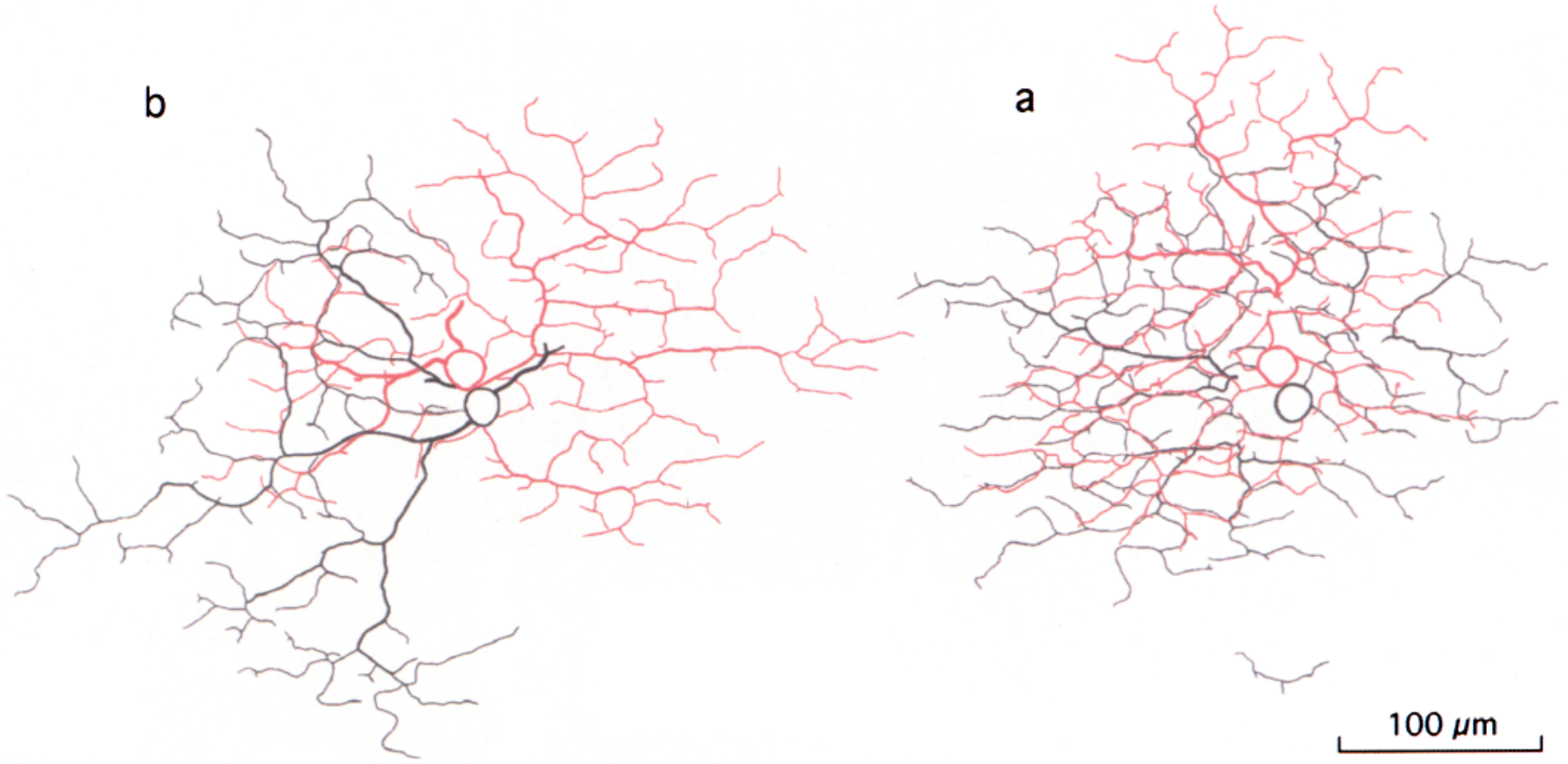

Figure 8. Graphic reconstruction of two BiS1 ganglion cells with overlapping dendritic fields in the On sublamina $(b)$ and the Off sublamina $(a)$. The black cell was injected with Lucifer Yellow and photographed under fluorescence excitation before the red cell was injected with Lucifer yellow; the fluorescence micrographs enabled the dendritic trees to be disentangled and separately mapped following the immunoperoxidase reaction. Retinal eccentricity: $2 \mathrm{~mm}$ below visual streak.

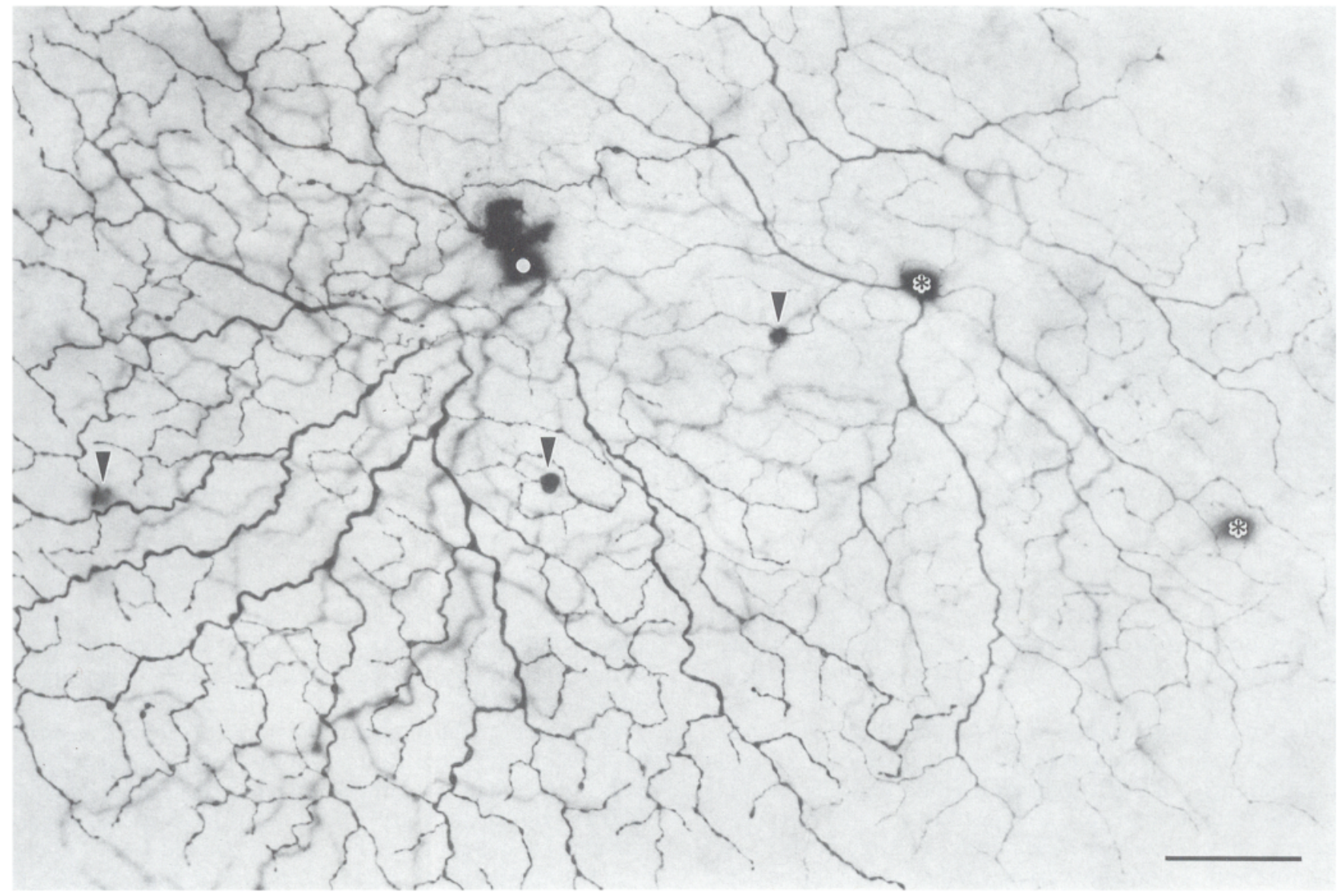

Figure 9. Micrograph of a Neurobiotin-injected BiS1 cell (white dot) and two tracer-coupled cells of the same subtype (asterisks), showing their dendritic arborizations in sublamina $a$. The injected ganglion cell also shows weak "inappropriate" coupling to three presumptive amacrine cells (arrowheads). Retinal eccentricity: $10 \mathrm{~mm}$ below visual streak. Scale bar, $50 \mu \mathrm{m}$. 


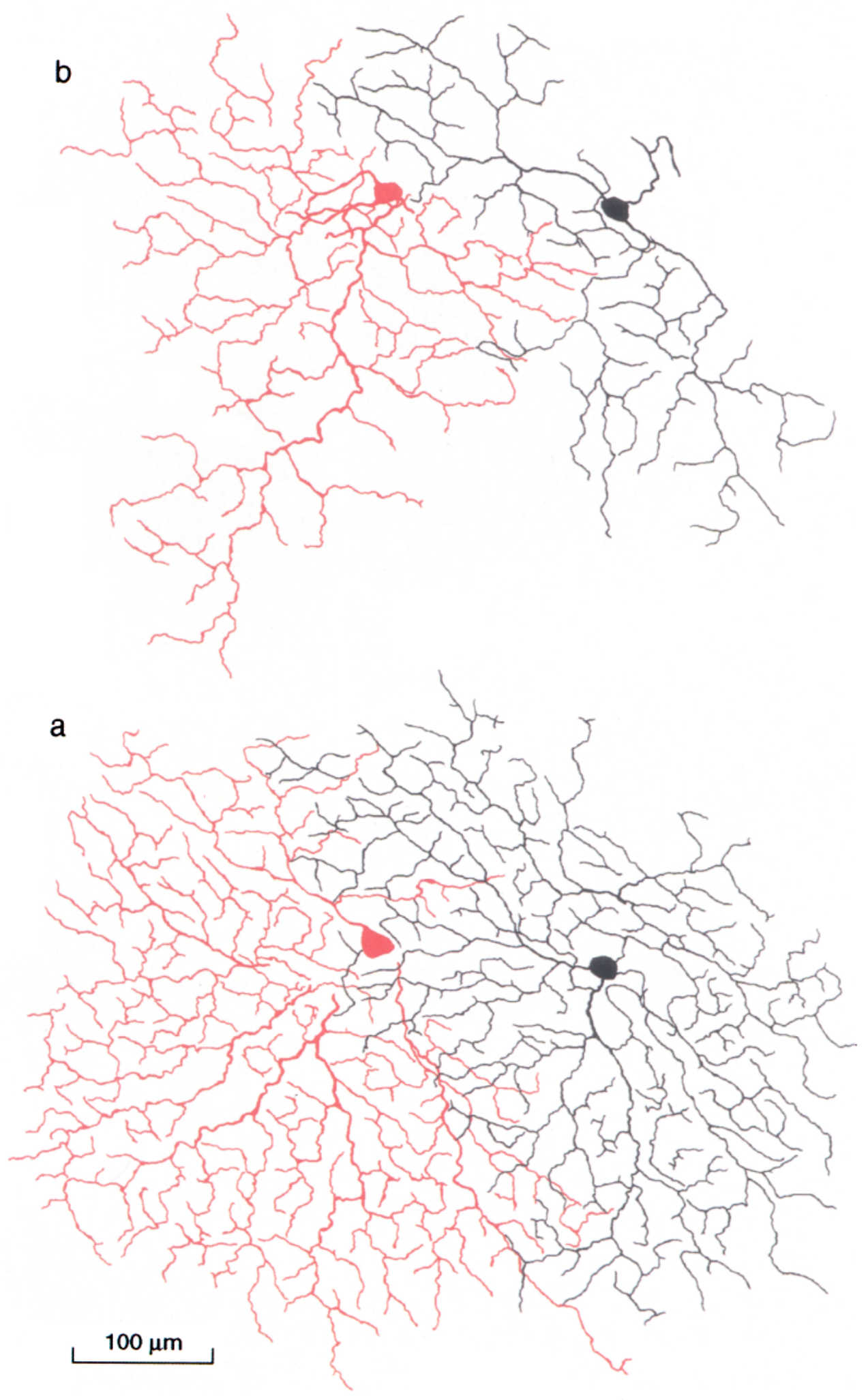

Figure 10. Graphic reconstruction of the tracer-coupled BiS1 cells illustrated in Figure 9, showing their dendritic arborizations in the On sublamina $(b)$ and the Off sublamina $(a)$.
Dendritic relationships of coupled BiS1 cells

The territorial organization of the coupled BiS1 cells reflected a striking pattern of dendritic architecture. The dendrites at the edge of the dendritic field often formed tip-to-shaft or tip-totip contacts with dendrites from coupled cells, thus appearing to form closed dendritic loops that may be equivalent to those found within the dendritic tree (Fig. 13). The dendritic-field tiling was most pronounced in sublamina $b$, where dendrites usually terminated at their first point of contact with a neighboring cell. Consequently, the dendritic trees of the coupled BiS1 cells provided almost seamless coverage of the retina, with the 

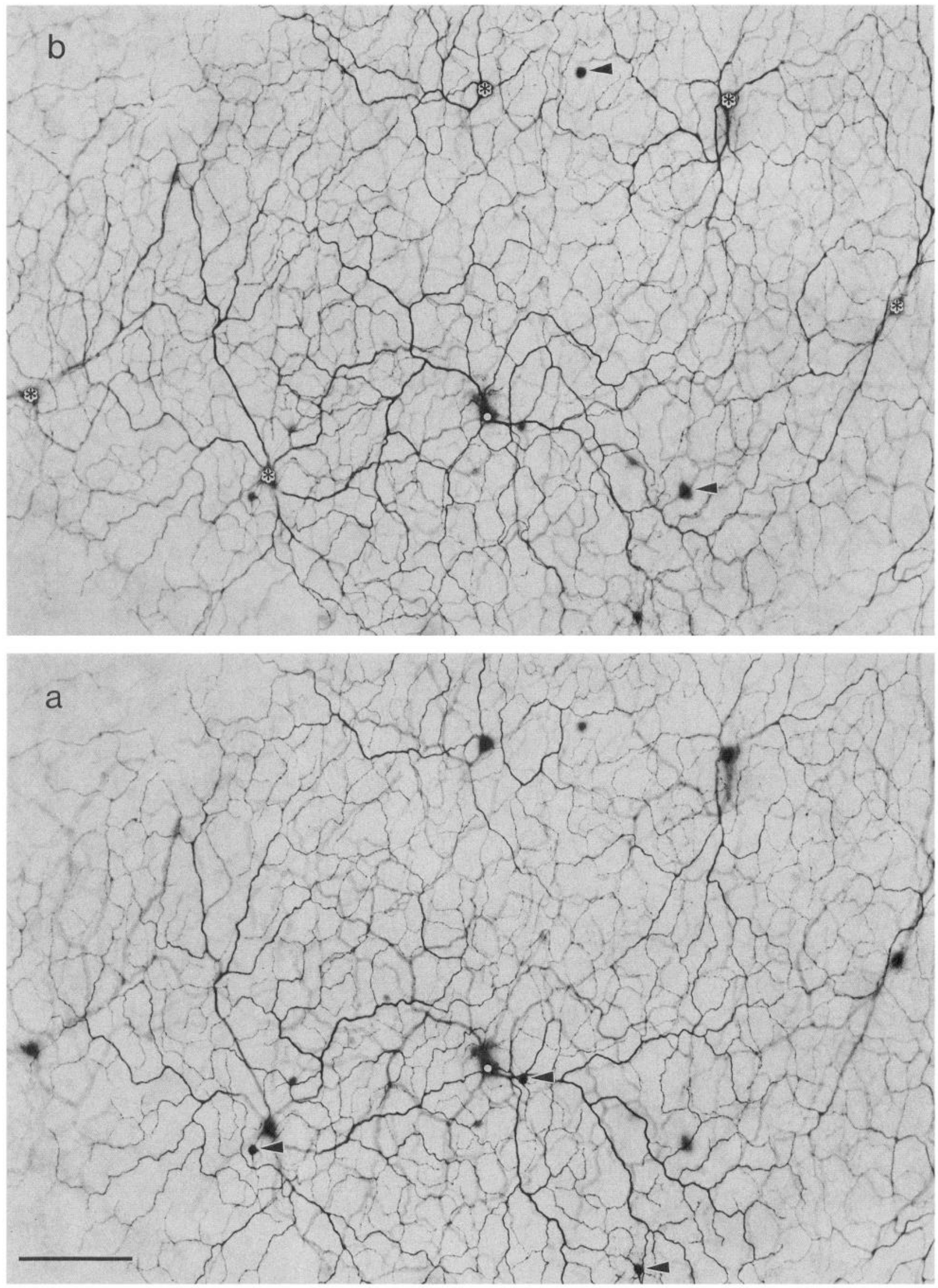

Figure 11. Micrographs of the extended dendritic plexus formed by a subtype of On-Off DS cells. The Neurobiotin-injected BiS1 cell (white dot) shows strong homologous coupling to seven neighboring BiS1 cells, five of whose somata are included here (asterisks). The dendrites of the tracercoupled cells form an ordered plexus in both the On sublamina $(b)$ and the Off sublamina $(a)$ of the inner plexiform layer. In addition, five isolated neurons of different types are weakly labeled (arrowheads), probably reflecting "inappropriate" coupling or artifactual coupling. Retinal eccentricity: $12 \mathrm{~mm}$ below visual streak. Scale bar, $100 \mu \mathrm{m}$. 
terminal dendrites of this subtype being distributed uniformly and economically across the retina.

The strong tracer coupling shown in Figure 11 enabled the fine structure of the dendritic plexus in sublamina $a$ to be compared with that in sublamina $b$ over an extended area (Fig. 14, top). This revealed that many of the dendrites in one sublamina followed the approximate course of dendrites in the other sublamina. When the sublamina a plexus was rotated $180^{\circ}$ about the center of the field (Fig. 14, bottom), the correspondence between the two patterns was markedly reduced, although this was not quantified in this study.

\section{Discussion}

\section{Subtypes of On-Off DS cells}

Two lines of evidence indicated that the tracer-coupled BiS1 cells comprised a single morphological subtype and thus corresponded to a single physiological subtype of On-Off DS cells. First, about $37 \%$ of the well-filled BiS1 cells showed traccr coupling in most retinae, indicating that coupling was not dependent on the state of the preparation. Second, when several BiS1 cells with closely spaced somata were injected with Neurobiotin, only one of the overlapping cells showed tracer coupling.

These results are compatible with the hypothesis that the BiS1 cells comprise three noncoupled subtypes, each accounting for about $20 \%$ of the cells, and one subtype that is homologously coupled, accounting for about $40 \%$ of the cells. The coupled BiS1 cells may correspond to the On-Off DS cells whose preferred direction is to the anterior because this physiological subtype comprised $38-44 \%$ of the On-Off DS units encountered during intraocular recording experiments (Oyster, 1968; Daw and Wyatt, 1974; He et al., 1992). On the other hand, the anterior subtype comprised only $23 \%$ of the On-Off DS units encountered by Amthor and colleagues during extracellular recordings from rabbit eyecup preparations (Oyster et al., 1993).

If the cell density of each noncoupled subtype was half that of the coupled subtype, then the dendritic-field area of the noncoupled BiS1 cells should be twice that of the coupled BiS 1 cells, presuming that each of the noncoupled subtypes also achieved complete coverage of the retina. However, the size of the coupled cells was similar to that of adjacent noncoupled cells, supporting the alternative hypothesis that the four subtypes of On-Off DS cells are present in equal numbers, with each subtype comprising about 10,000 ganglion cells or $3 \%$ of the total population. The On-Off DS cells usually account for $21-26 \%$ of the ganglion cells encountered with extracellular recording electrodes in the rabbit retina (Oyster, 1968; Daw and Wyatt, 1974; Caldwell and Daw, 1978; Vaney et al., 1981; cf. Levick, 1967), but this oversampling can be attributed to their relatively large somata (Amthor et al., 1989) and axons (Vaney et al., 1981), analogous to the high encounter frequencies of $\alpha$-ganglion cells in the cat retina (Cleland et al., 1975).

A recent abstract by Amthor and Oyster (1993) directly confirmed that neighboring On-Off DS cells with the same preferred direction tiled the retina with minimal overlap and, moreover, this territorial organization was shown by each of the four subtypes of On-Off DS cells. They independently reported that overlapping cells with different preferred directions have fasciculated dendrites, but they did not test whether any of the subtypes showed tracer coupling when injected with biocytin or Neurobiotin.

\section{Dendritic territories of retinal ganglion cells}

The territorial organization of the dendritic trees of the coupled subtype resembles, on a larger scale, the territorial organization of the branching systems of individual On-Off DS cells (Oyster et al., 1993). This suggests that similar dendritic interactions shape both the branching pattern and the spatial extent of these cells (compare Figs. 2, 12). Thus, the closed dendritic loops found within the dendritic tree of individual On-Off DS cells (Amthor et al., 1984) may be an internal expression of the tipto-shaft contacts formed between the dendrites of neighboring cells. However, most of the terminal dendrites within the cell do not make such contacts. This suggests that if the dendrites simply grow until they contact another dendrite of the same subtype, then contact between dendrites from the same cell is usually followed by retraction.

The dendritic-field organization of the On-Off DS cells differs in several ways from that reported for other types of retinal ganglion cells. The shape and size of the coupled BiSl cells cannot be predicted from the somatic array whereas, for each subtype (On or Off) of $\alpha$-ganglion cells, the overlapping dendritic domains are delimited by the neighboring somata (Wässle et al., 1981 b; Peichl et al., 1987; Dacey and Brace, 1992). Moreover, the On $\alpha$-cells in rabbit retina showed only a 1.5 -fold variation in dendritic-field area at each retinal eccentricity (Peichl et al., 1987). By contrast, the eight coupled BiSl cells reconstructed in Figure 12 showed at least a fourfold variation in dendritic-field area within each sublamina, but only a 1.6-fold variation in the summed fields from both sublaminae. Thus, the total amount of dendrite produced by neighboring BiS1 cells was rather constant, but its distribution between the two sublaminae appeared haphazard when viewed in isolation.

The monoamine-accumulating (MA) ganglion cells in the cat retina showed a two- to threefold coverage of their dendritic fields (Dacey, 1989), comparable to the coverage of each subtype of the $\alpha$-cells in cat retina and the parasol cells in macaque retina (Dann et al., 1988; Dacey and Brace, 1992). The dendritic trees of the MA ganglion cells were not randomly superimposed but tended to interdigitate so as to minimize the number of dendritic crossings and maintain a uniform dendritic density across the region of overlap (Dacey, 1989). This resembles the dendritic organization of the BiSl ganglion cells, particularly in sublamina $a$ where the overlap appears to be greater. Dacey (1993) recently reported that each subtype (On or Off) of the midget ganglion cells provided almost complete coverage of the human retina with virtually no overlap. The dendrites of neighboring midget cells rarely crossed or touched, and thus, these cells appear even more territorial than the coupled BiS1 cells.

\section{Neuronal coupling of DS cells}

Previous studies demonstrated that the complex pattern of tracer coupling shown by the AII amacrine cells accurately reflected the connectivity of their gap junctions (Vaney, 1991; Hampson et al., 1992). Thus, the homologous tracer coupling shown by the BiS1 cells can be parsimoniously attributed to the presence of gap junctions at dendritic contacts between neighboring cells of the coupled subtype. Moreover, the tip-to-shaft and tip-totip contacts made by the tracer-coupled BiSl cells resembled those made by electrically coupled amacrine cells in fish retinae (Negishi and Teranishi, 1989, 1990; Teranishi and Negishi, 1991); in some cases, electron microscopy confirmed that the fish amacrine cells were connected by gap junctions (Naka and 


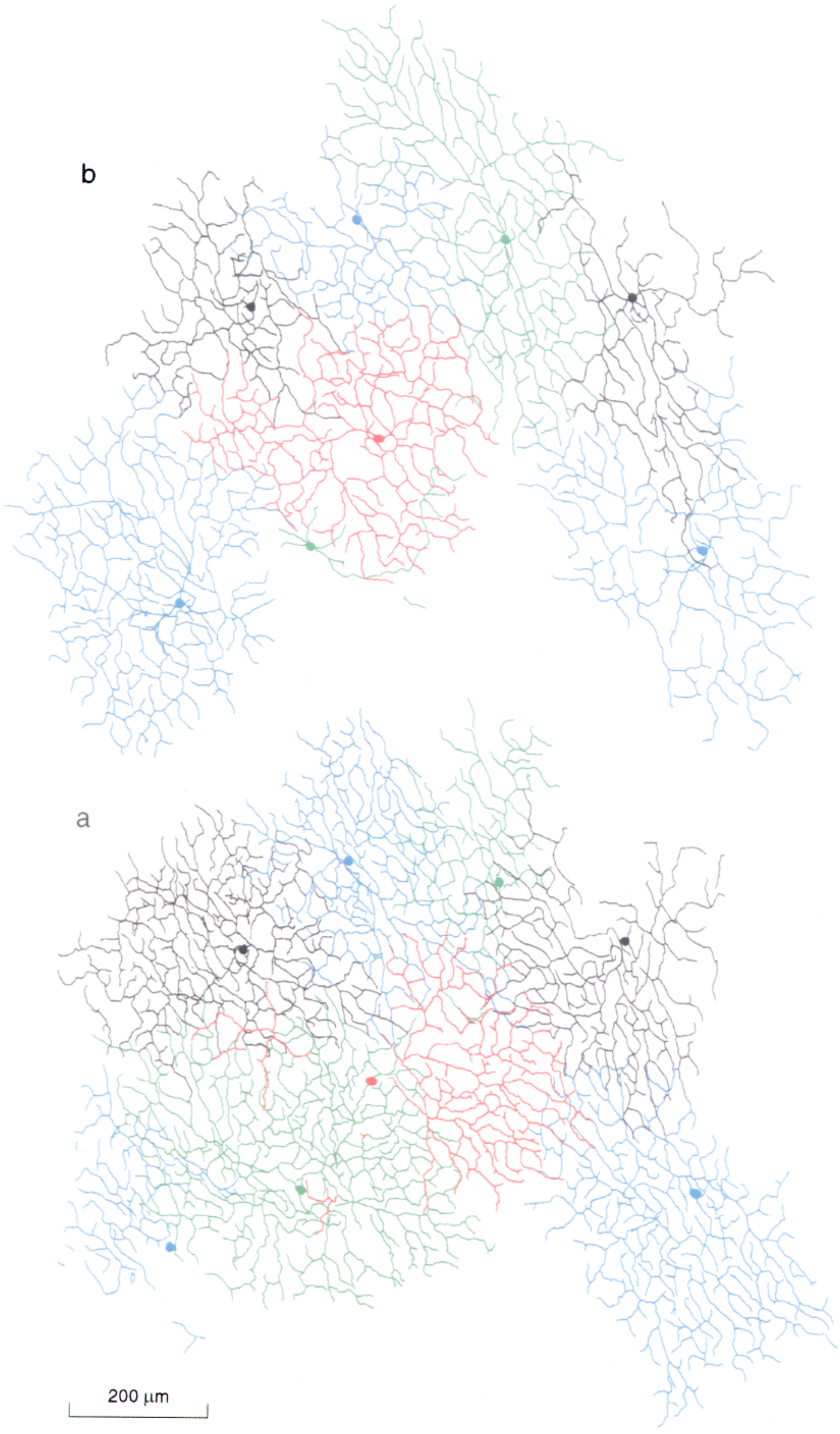




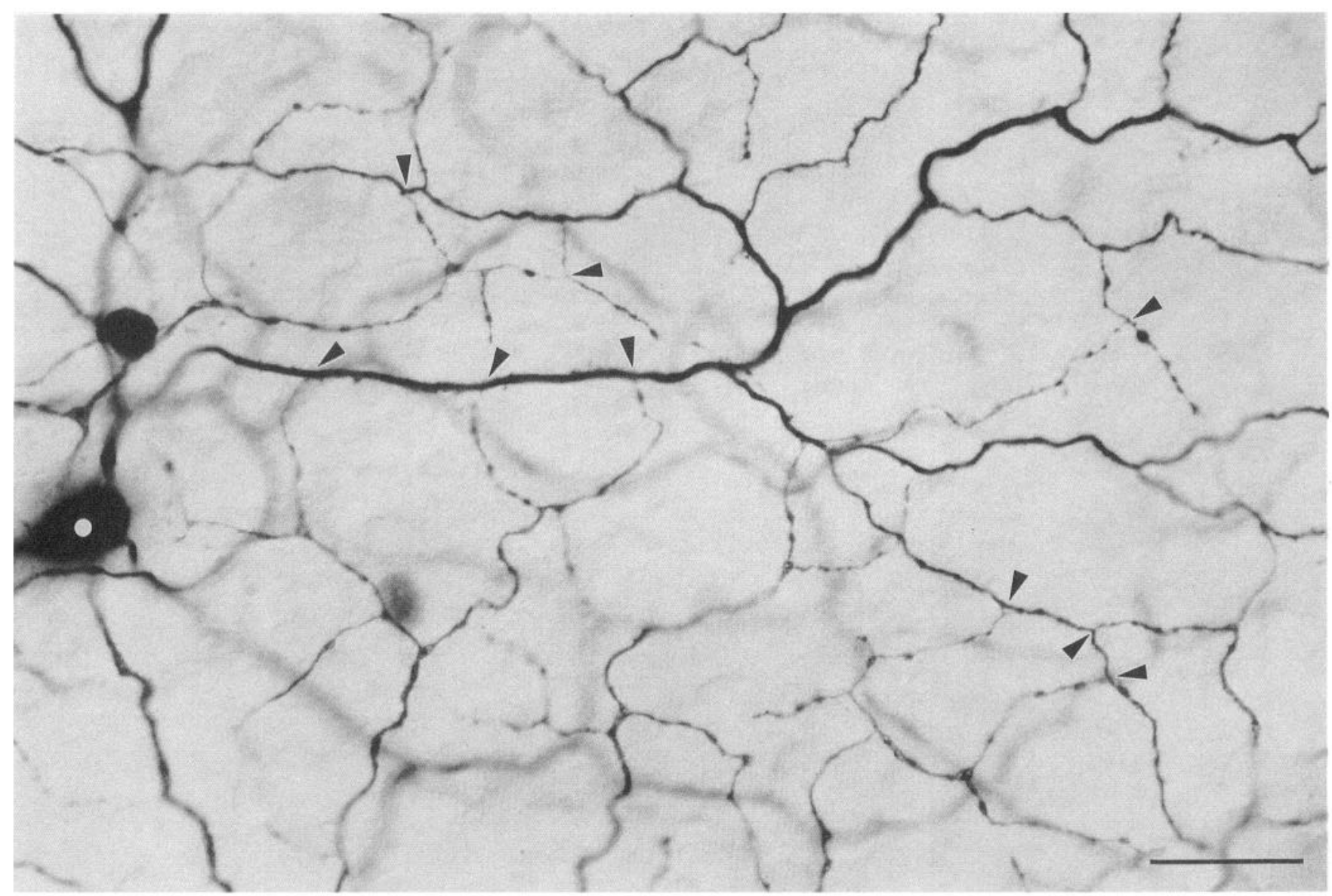

Figure 13. High-power micrograph showing the overlapping dendritic trees of an injected BiS1 cell (white dot) and a tracer-coupled neighbor, corresponding to the red cell and the lower green cell of Figure 12a, respectively. Arrowheads mark the tip-to-shaft dendritic contacts in sublamina a. Scale bar, $25 \mu \mathrm{m}$.

Christensen, 1981; Zimmerman, 1983; Negishi et al., 1991; Hidaka et al., 1993).

On the other hand, there appear to be no reports from ultrastructural studies that ganglion cells make gap junctions in any retina. It is possible, however, that such gap junctions may not be recognized in ultrathin sections, given that freeze-fracture studies on mammalian retinae (Raviola and Raviola, 1982) revealed that many of the gap junctions in the inner plexiform layer are quite small or comprise loosely arranged connexons enclosing islands of particle-free membrane. Another possibility is that tracer coupling may also be mediated by other types of intercellular junctions. Famiglietti (1991) reported that the fasciculated dendrites of presumptive On-Off DS cells were connected by puncta adherentia, but these probably involved overlapping cells of different subtypes and, therefore, would not account for the pattern of tracer coupling observed in this study.

If the tracer-coupled BiS1 cells are connected by gap junctions, then the receptive fields of the corresponding subtype of OnOff DS cells should be significantly larger than the dendritic fields. However, recordings made by Yang and Masland (1992) from isolated rabbit retina indicated that the receptive field closely matched the dendritic field for all subtypes of the OnOff DS cells. Again, it is not known whether any of the cells would show tracer coupling under their experimental conditions.

Similar findings have been reported for the AII amacrine cells in rabbit retina: these narrow-field neurons are homologously coupled by small gap junctions (Dacheux and Raviola, 1986; Strettoi et al., 1992) that readily pass biotinylated tracers (Vaney, 1991), but their receptive fields are not significantly larger than their dendritic fields in dark-adapted eyecup preparations (Bloomfield, 1992). However, it now appears that dim background illumination produces a dramatic increase in both the extent of tracer coupling and the receptive-field size of the AII cells (Xin et al., 1994). It thus seems plausible that the illumination level might also affect the strength of coupling between the On-Off DS cells.

\section{Dendritic fasciculation}

What is the functional significance of the dendritic fasciculation of overlapping BiS1 cells, which presumably comprise On-Off DS cells with different preferred directions? The On-Off DS

Figure 12. Graphic reconstruction of the tracer-coupled BiS1 ganglion cells illustrated in Figure 11, showing the dendritic plexus in the On sublamina $(b)$ and the Off sublamina $(a)$. The Neurobiotin-injected BiS1 cell $($ red $)$ is homologously coupled to seven neighboring cells $($ blue, black, green), presumably comprising On-Off DS cells with the same preferred direction. 

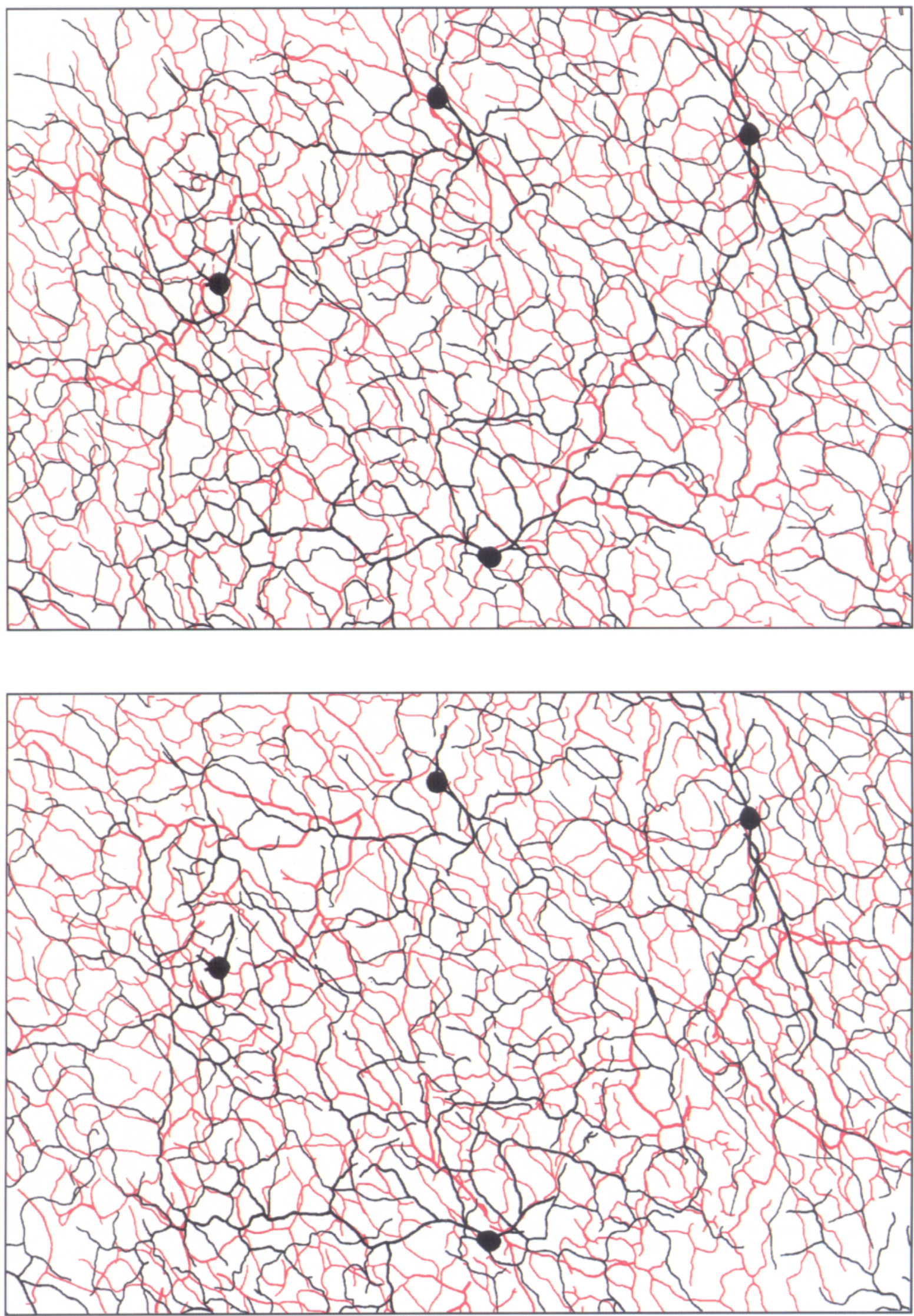

Figure 14. Top, Graphic reconstruction of the central portion $(500 \times 700 \mu \mathrm{m})$ of the dendritic plexus illustrated in Figures 11 and 12 , showing that dendrites in sublamina $a(\mathrm{red})$ often follow the approximate course of dendrites in sublamina $b($ black). Bottom, When the sublamina $a$ plexus is rotated $180^{\circ}$ about the center of the field, the correspondence between the two patterns is markedly reduced. 
cells receive much of their excitatory drive from mirror-symmetric populations of cholinergic amacrine cells (Masland and Ames, 1976; Ariel and Daw, 1982), which costratify narrowly with the BiSl ganglion cells (Famiglietti, 1987, 1992b). The processes of the cholinergic amacrine cells also form loose fascicles (Tauchi and Masland, 1985; Brandon, 1987; Famiglietti and Tumosa, 1987) that follow the course of BiSl dendrites (Vaney et al., 1989). Moreover, the pattern of the cholinergic meshwork in sublamina $a$ shows a good correspondence with that in sublamina $b$ (Brandon, 1987; Famiglietti and Tumosa, 1987), and this appears to be reflected in the correspondence between the two arborizations of the coupled BiS1 cells (Fig. 14).

The striking dendritic fasciculation suggests that a small neuronal assemblage, comprising a bundle of ganglion cell dendrites running a "gauntlet" of presynaptic amacrine boutons and bipolar terminals (Brandon, 1987; Famiglietti, 1991), may contain all the neuronal wiring that is necessary for abstracting image motion in four orthogonal directions. Such fasciculation would facilitate contact between the processes of presynaptic neurons and the dendrites of the On-Off DS cells, enabling each process to provide simultaneous input to the four overlapping subtypes, as required by several related models of direction selectivity that are characterized by their neuronal parsimony (Vaney, 1990a; Borg-Graham and Grzywacz, 1992).

\section{References}

Amthor FR, Oyster CW (1993) Relation between preferred direction and dendritic organization of identified, contacting On-Off DS ganglion cells and Ach. amacrine cells in rabbit retina. Soc Neurosci Abstr 19:1258.

Amthor FR, Takahashi ES, Oyster CW (1984) Morphology of on-off direction-selective ganglion cells in the rabbit retina. Brain Res 298: 187-190.

Amthor FR, Takahashi ES, Oyster CW (1989) Morphologies of rabbit retinal ganglion cells with complex receptive fields. J Comp Neurol 280:97-121.

Ariel M, Daw NW (1982) Pharmacological analysis of directionally sensitive rabbit retinal ganglion cells. J Physiol (Lond) 324:161-185.

Barlow HB, Hill RM, Levick WR (1964) Retinal ganglion cells responding selectively to direction and speed of image motion in the rabbit. J Physiol (Lond) 173:377-407.

Bloomfield SA (1992) Relationship between receptive and dendritic field size of amacrine cells in the rabbit retina. J Neurophysiol 68 : 711-725.

Borg-Graham LJ, Grzywacz NM (1992) A model of the directional selectivity circuit in retina: transformations by neurons singly and in concert. In: Single neuron computation (McKenna T, Davis J, Zornetzer SF, eds), pp 347-375. San Diego: Academic.

Brandon C (1987) Cholinergic neurons in the rabbit retina: dendritic branching and ultrastructural connectivity. Brain Res 426:119-130.

Caldwell JH, Daw NW (1978) New properties of rabbit retinal ganglion cells. J Physiol (Lond) 276:257-276.

Cleland BG, Levick WR, Wässle H (1975) Physiological identification of a morphological class of cat retinal ganglion cells. J Physiol (Lond) 248:151-171.

Dacey DM (1989) Monoamine-accumulating ganglion cell type of the cat's retina. J Comp Neurol 288:59-80.

Dacey DM (1993) The mosaic of midget ganglion cells in the human retina. I Neurosci 13:5334-5355.

Dacey DM, Brace S (1992) A coupled network for parasol but not midget ganglion cells in the primate retina. Vis Neurosci 9:279-290.

Dacheux RF, Raviola E (1986) The rod pathway in the rabbit retina: a depolarizing bipolar and amacrine cell. J Neurosci 6:331-345.

Dann JF, Buhl EH, Peichl L (1988) Postnatal dendritic maturation of alpha and beta ganglion cells in cat retina. J Neurosci 8:1485-1499.

Daw NW, Wyatt HJ (1974) Raising rabbits in a moving visual environment: an attempt to modify directional sensitivity in the retina. J Physiol (Lond) 240:309-330.
Famiglietti EV (1987) Starburst amacrine cells in cat retina are associated with bistratified, presumed directionally selective, ganglion cells. Brain Res 413:404-408.

Famiglietti EV (1991) Synaptic organization of starburst amacrine cells in rabbit retina: analysis of serial thin sections by electron microscopy and graphic reconstruction. J Comp Neurol 309:40-70.

Famiglietti EV (1992a) New metrics for analysis of dendritic branching patterns demonstrating similarities and differences in $\mathrm{ON}$ and $\mathrm{ON}-$ OFF directionally selective retinal ganglion cells. J Comp Neurol 324: 295-321.

Famiglietti EV (1992b) Dendritic co-stratification of ON and ONOFF directionally selective ganglion cells with starburst amacrine cells in rabbit retina. J Comp Neurol 324:322-335.

Famiglietti EV, Tumosa N (1987) Immunocytochemical staining of cholinergic amacrine cells in rabbit retina. Brain Res 413:398-403.

Hampson ECGM, Vaney DI, Weiler R (1992) Dopaminergic modulation of gap junction permeability between amacrine cells in mammalian retina. J Neurosci $12: 4911-4922$.

He S-H, Vaney DI, Levick WR (1992) The preferred direction of the tracer coupled direction selective retinal ganglion cells may be to the anterior. Proc Aust Neurosci Soc 3:170.

Hidaka S, Maehara M, Umino O, Lu Y, Hashimoto Y (1993) Lateral gap junction connections between retinal amacrine cells summating sustained responses. Neuroreport 5:29-32.

Horikawa K, Armstrong WE (1988) A versatile means of intracellular labeling: injection of biocytin and its detection with avidin conjugates. J Neurosci Methods 25:1-11.

Hughes A (1985) New perspectives in retinal organization. Prog Retinal $\operatorname{Res} 4: 243-313$.

Kaneko A, Nishimura Y, Tauchi M, Shimai K (1981) Morphological observation of retinal cells presumably made syncytial by an electrode penetration. J Neurosci Methods 4:299-303.

Kita H, Armstrong WE (1991) A biotin-containing compound $\mathrm{N}$-(2aminoethyl) biotinamide for intracellular labeling and neuronal tracing studies: comparison with biocytin. J Neurosci Methods 37:141150.

Levick WR (1967) Receptive fields and trigger features of ganglion cells in the visual streak of the rabbit's retina. J Physiol (Lond) 188: 285-307.

Masland RH, Ames A (1976) Responses to acetylcholine of ganglion cells in an isolated mammalian retina. J Neurophysiol 39:1220-1235.

Masland RH, Mills JW, Hayden SA (1984) Acetylcholine-synthesizing amacrine cells: identification and selective staining by using radioautography and fluorescent markers. Proc R Soc Lond [Biol] 223:79100.

Naka K, Christensen BN (1981) Direct electrical connections between transient amacrine cells in the catfish retina. Science 214:462-464.

Negishi K, Teranishi T (1989) Dendritic morphology of a class of interstitial amacrine cells in carp retina. In: NATO ASI series, Vol H31, Neurobiology of the inner retina (Weiler R, Osborne NN, eds), pp 133-143. Berlin: Springer.

Negishi K, Teranishi T (1990) Close tip-to-tip contacts between dendrites of transient amacrine cells in carp retina. Neurosci Lett 115: $1-6$.

Negishi K, Teranishi T, Sugawara K, Wagner H-J (1991) Dendritic contacts between neighboring homologous amacrine cells in carp retina. Neurosci Res 15:S145-S155.

Oyster CW (1968) The analysis of image motion by the rabbit retina. J Physiol (Lond) 199:613-635.

Oyster CW, Barlow HB (1967) Direction-selective units in rabbit retina: distribution of preferred directions. Science 155:841-842.

Oyster CW, Takahashi ES, Hurst DC (1981) Density, soma size, and regional distribution of rabbit retinal ganglion cells. J Neurosci 1:13311346.

Oyster CW, Takahashi ES, Fry KR, Lam DM-K (1987) Ganglion cell density in albino and pigmented rabbit retinas labeled with a ganglion cell-specific monoclonal antibody. Brain Res 425:25-33.

Oyster CW, Amthor FR, Takahashi ES (1993) Dendritic architecture of ON-OFF direction-selective ganglion cells in the rabbit retina. Vision Res 33:579-608.

Peichl L, Buhl EH, Boycott BB (1987) Alpha ganglion cells in the rabbit retina. J Comp Neurol 263:25-41.

Pow DV, Wright LL, Crook D, Vaney DI (1993) Production of ultrahigh titre antisera for use in neural tracing and immunocytochemical studies. Proc Aust Neurosci Soc 4:94. 
Provis JM (1979) The distribution and size of ganglion cells in the retina of the pigmented rabbit: a quantitative analysis. J Comp Neurol 185:121-138.

Raviola E, Raviola G (1982) Structure of the synaptic membranes in the inner plexiform layer of the retina: a freeze-fracture study in monkeys and rabbits. J Comp Neurol 209:233-248.

Strettoi E, Raviola E, Dacheux RF (1992) Synaptic connections of the narrow-field, bistratified rod amacrine cell (AII) in the rabbit retina. J Comp Neurol 325:152-168.

Tauchi M, Masland RH (1985) Local order among the dendrites of an amacrine cell population. J Neurosci 5:2494-2501.

Teranishi T, Negishi K (1991) Dendritic morphology of a class of interstitial and normally placed amacrinc cclls revcalcd by intraccllular Lucifer yellow injection in carp retina. Vision Res 31:463-475.

Vaney DI (1980) A quantitative comparison between the ganglion cell populations and axonal outflows of the visual streak and periphery of the rabbit retina. J Comp Neurol 189:215-233.

Vaney DI (1984) 'Coronate' amacrine cells in the rabbit retina have the 'starburst' dendritic morphology. Proc R Soc Lond [Biol] 220: 501-508.

Vaney DI (1990a) The mosaic of amacrine cells in the mammalian retina. Prog Retinal Res 9:49-100.

Vaney DI (1990b) Biocytin dye-coupling reveals subpopulations of direction-selective ganglion cells in rabbit retina. Proc Aust Neurasci Soc 1:136.

Vaney DI (1991) Many diverse types of retinal neurons show tracer coupling when injected with biocytin or Neurobiotin. Neurosci Lett 125:197-190.

Vaney DI (1992) Photochromic intensification of diaminobenzidine reaction product in the presence of tetrazolium salts: applications for intracellular labeling and immunohistochemistry. J Neurosci Methods 44:217-223.

Vaney DI (1993) Dendritic plexus of direction selective ganglion cells in rabbit retina. Invest Ophthalmol Vis Sci 34:985.

Vaney DI (1994) Patterns of neuronal coupling in the retina. Prog Retinal Eye Res 13:301-355.

Vaney DI, Levick WR, Thibos LN (1981) Rabbit retinal ganglion cells: receptive field classification and axonal conduction properties. Exp Brain Res 44:27-33.

Vaney DI, Collin SP, Young HM (1989) Dendritic relationships between cholinergic amacrine cells and direction-selective retinal ganglion cells. In: NATO ASI Series, Vol H31, Neurobiology of the inner retina (Wcilcr R, Osbornc NN, cds), pp 157-168. Berlin: Springer.

Wässle H, Peichl L, Boycott BB (1981a) Morphology and topography of on- and off-alpha cells in the cat retina. Proc R Soc Lond [Biol] 212:157-175.

Wässle H, Peichl L, Boycott BB (1981b) Dendritic territories of cat retinal ganglion cells. Nature 292:344-345.

Xin D, Bloomfield SA, Persky SE (1994) Effect of background illumination on receptive field and tracer-coupling size of horizontal cells and AII amacrine cells in the rabbit retina. Invest Ophthalmol Vis Sci 35:1363.

Yang G, Masland RH (1992) Direct visualization of the dendritic and receptive fields of directionally selective retinal ganglion cells. Science 258:1949-1952.

Zimmerman RP (1983) Bar synapses and gap junctions in the inner plexiform layer: synaptic relationships of the interstitial amacrine cell of the retina of the cichlid fish, Astronotus ocellatus. J Comp Neurol $218: 471-479$. 